\title{
As Políticas para os Povos Tradicionais à luz da experiência das Raizeiras do Cerrado - Articulação Pacari
}

The Politics for Traditional People in light of the experience from the Raizeiras do Cerrado - Articulação Pacari

\section{Carolina Alves}

\section{carolinalveseng@gmail.com}

Bacharel em Relações Internacionais PUC-Rio.

\section{Laura Reimann}

laurareimann1996@gmail.com

Graduanda em Biologia - PUC-Rio.

\section{Resumo}

Este artigo visa contribuir para o entendimento da situação dos povos e comunidades tradicionais, tendo em vista a experiência das Raizeiras do Cerrado. Valendo-se de textos acadêmicos e do governo e entrevistas com representante das raizeiras, o texto fornece ao leitor insumos para avaliar a atuação do governo brasileiro em relação aos povos e comunidades tradicionais.

Palavras-chave: raizeira; cerrado; governo; povos tradicionais; políticas públicas;

\begin{abstract}
The present article aims to contribute do the understanding of the situation of traditional people and communities, through the experience of the "Raizeiras do Cerrado". Through academic and governmental papers and interviews with representatives of the "Raizeiras", the article provides the reader inputs to evaluate the performance of Brazilian government when it comes to traditional people and communities.
\end{abstract}

Keywords: raizeira; cerrado; government; traditional people; public policies; 


\section{Introdução}

Este artigo visa analisar a situação das raizeiras enquanto uma comunidade tradicional, levando em consideração a sua manutenção e as políticas públicas que as envolvem, tendo como foco a Articulação Pacari de Plantas Medicinais do Cerrado.

Os argumentos apresentados têm por base autores como Elizabetsky \& Souza, Machado, Ramos Neto, Prance, Cunha e informações retiradas do site do Ministério da Saúde e da Articulação Pacari. Além disso, conta também com uma entrevista e um questionário feito a representantes da Articulação Pacari, em uma tentativa de se compreender a partir da visão da comunidade tradicional como tem sido sua atuação até então, e a sua relação com o governo.

Por meio do entendimento da Articulação Pacari e de seu trabalho em termos socioambientais e políticos, ao fim desse artigo espera-se que o leitor compreenda a importância da continuidade do projeto desenvolvido pela comunidade e da necessidade de reconhecimento e apoio de instâncias do governo, principalmente com todo o retrocesso de legislações socioambientais e do aumento do desmatamento observado nos últimos anos.

\section{Articulação Pacari}

A Articulação Pacari é uma rede de mulheres diversas com atuação socioambiental, formada por organizações comunitárias que praticam a medicina tradicional através do uso sustentável dos recursos naturais do Cerrado. Com isso, promove geração de trabalho e renda através do desenvolvimento da cadeia produtiva dos óleos de macaúba, pequi, rufão, indaiá e gueroba, comercializados pela marca "Pacari Cerrado Ecoprodutivo".

A Pacari foi criada em 1999 a partir da articulação da Rede Cerrado e da Rede de Plantas Medicinais da América do Sul. Após a realização de diagnósticos participativos junto a diversos grupos organizados, que visou identificar as potencialidades e desafios de cada grupo, o trabalho articulado se tornou possível, e hoje abrange cerca de 50 organizações nos estados de Minas Gerais, Goiás, Tocantins e Maranhão. O trabalho da Articulação envolve "pesquisa popular, assessoria, intercâmbio, capacitação, produção e registro de conhecimentos, publicação, realização de encontros e participação em espaços de formulação de políticas públicas” (PACARI, 2016). 
A Articulação participou da formulação da Farmacopeia Popular do Cerrado ${ }^{1}$ publicada em 2009, sob forte oposição da Anvisa (Agência Nacional de Vigilância Sanitária) devido à nomenclatura dada de "farmacopeia". Para a agência, essa terminologia designa um "conjunto de informações técnicas que retratam a nomenclatura das substâncias, dos medicamentos básicos (princípios ativos e coadjuvantes), requisitos de qualidade, insumos, compostos e equipamentos farmacêuticos" e, portanto, não poderia ser utilizada para se referir à farmacopeia popular. Foi sugerida a troca do nome para Guia de Plantas Medicinais. O fato de ter sido publicada com o nome de farmacopeia confere a ela um caráter político, que seria perdido se o nome fosse alterado de acordo com a demanda da Anvisa. A Farmacopeia foi formulada após cinco anos de pesquisa, com a ajuda de 262 raizeiras, raizeiros e representantes de farmacinhas comunitárias, e se torna uma referência teórica para a segurança de indicação de remédios caseiros no dia a dia. Apesar da batalha com a Anvisa, a publicação teve apoio do governo por meio do Ministério do Meio Ambiente, e contou com o financiamento de entidades como a Coordenadoria Ecumênica de Serviço (CESE), o Programa de Pequenos Projetos Ecossociais (PPP - ECOS), a Misereor (entidade da Igreja Católica Alemã que trabalha com cooperação para o desenvolvimento) para as etapas de sistematização, realização dos encontros e pesquisa em campo.

Em termos políticos, a Articulação é membro do Comitê Nacional de Plantas Medicinais e Fitoterápicos e da Comissão Nacional de Desenvolvimento Sustentável de Povos e Comunidades Tradicionais, e tem como propósito o reconhecimento da prática da medicina popular, a proteção do Cerrado, bioma do qual são altamente dependentes e tem sofrido um aumento do desmatamento e da degradação, e o reconhecimento da importância de seus saberes tradicionais. Ainda, o conhecimento detido pela comunidade tradicional acerca de aspectos ecológicos é de alta relevância para a preservação ambiental do seu meio de convívio (CUNHA, 2007), o bioma Cerrado. Atualmente, ele sofre com o aumento da pressão antrópica, vista na excessiva exploração dos recursos hídricos, perda de enorme parte de sua cobertura vegetacional e biodiversidade de fauna e flora para, principalmente, as enormes monoculturas de soja que ocupam extensões enormes do território do bioma (BANDEIRA; CAMPOS, 2018).

O uso das plantas medicinais pelas raizeiras é baseado em um conhecimento milenar, passado de geração a geração pela força da oralidade - que hoje conta com a ajuda de vias tecnológicas para que haja registros desses conhecimentos que vêm se perdendo na atualidade

\footnotetext{
1 Documento completo disponível em: http://www.mma.gov.br/estruturas/sbf_agrobio/_publicacao/89_publicacao01082011054912.pdf

DIGNIDADE RE-VISTA | ISSN2525-698X| 2018 | V. IV | N. 8 | Políticas Públicas e Direitos Humanos. Pastoral Universitária Anchieta PUC-RIO.
} 
pela falta de interesse dos mais jovens. A relação próxima das comunidades tradicionais com o meio ambiente cria uma enorme consciência ambiental acerca do manejo dos recursos biológicos (DIEGUES et al., 2000) que são a matéria prima para que haja a produção dos medicamentos tradicionais, assim como a base da alimentação das comunidades tradicionais como um todo. O uso sustentável dos recursos os torna mais duráveis. O conhecimento detido pelas raizeiras e outras comunidades sobre o melhor tipo de plantio para cada espécie, o período do plantio e o momento correto da colheita, a quantidade que deve ser retirada do meio, etc, torna possível uma relação estreita do homem e do meio, uma vez que há respeito dos limites e os ciclos da natureza.

A medicina tradicional, seus usos e as formas terapêuticas exercidas pelas raizeiras do Cerrado - e hoje registradas em sua Farmacopeia Popular - trazem luz à importância dos estudos etnobotânicos, que contribuem para o manejo de ecossistemas e planos de conservação (PRANCE, 1995), além de servir como ferramenta para a indústria farmacêutica (ELISABETSKY \& SOUZA, 2004). O conhecimento acerca das funções fisiológicas das plantas é um elemento valorizado por pesquisadores que atuam no desenvolvimento de novos fármacos.

No desenvolvimento de seu trabalho a Articulação conta com o auxílio de alguns parceiros financeiros e institucionais, que colaboram com recursos e com projetos. Este é o caso do Instituto Sociedade Populações e Natureza (ISPN) através do PPP - ECOS, da Fundação Heinrich Böll, da Fundação Luterana de Diaconia (FLD), da Rede de Intercâmbio de Tecnologias Alternativas.

\section{Desafios e oportunidades encarados em relação às políticas públicas}

Falar do uso de plantas medicinais é falar também de políticas públicas, um dos focos de atuação da Articulação por meio da capacitação de organizações comunitárias e da elaboração de propostas articuladas entre elas. As políticas públicas visadas almejam a legalização da atividade. As leis existentes não são articuladas entre si e falham em traduzir corretamente o significado e o valor da prática da medicina tradicional para os povos que dependem dela (PACARI, 2016).

Em 2008, foi criado o Comitê Nacional de Plantas Medicinais e Fitoterápicos coordenado pela Secretaria de Ciência, Tecnologia e Insumos Estratégicos do Ministério da Saúde - SCTIE/MS. O objetivo do comitê é monitorar o Programa Nacional de Plantas 
Medicinais e Fitoterápicos, verificar a ampliação das opções terapêuticas aos usuários e a garantia de acesso a plantas medicinais e fitoterápicos em serviços relacionados ao SUS. Como representante do bioma Cerrado, a Articulação Pacari tem direito a um assento no Comitê, desde a sua criação. Sua atuação garantiu a inclusão da Diretriz 10 no Programa Nacional de Plantas Medicinais e Fitoterápicos que versa sobre a promoção e reconhecimento das práticas populares de uso de plantas medicinais e remédios caseiros.

De acordo com Lourdes Laureano e Jaqueline Dias², representantes da Articulação, a primeira tentativa de se organizar a Política Nacional de Desenvolvimento Sustentável dos Povos e Comunidades Tradicionais - uma política para garantir os direitos desses povos, tirálos da posição de invisibilidade perante a sociedade e as políticas públicas, e afirmar os deveres do poder público para com eles - ocorreu em uma reunião com as principais lideranças dos povos. Essa reunião deu origem à Comissão Nacional de Desenvolvimento Sustentável de Povos e Comunidades Tradicionais, promulgada pelo Poder Executivo em 2006, com o objetivo de, futuramente, se tornar um conselho e formular as diretrizes para a Política Nacional. Por 10 anos, a Comissão exerceu suas atividades, até que, às vésperas de sofrer o processo de impeachment, a presidenta Dilma Rousseff assinou o decreto promulgando o Conselho Nacional de Desenvolvimento Sustentável de Povos e Comunidades Tradicionais, que conta com a participação da sociedade civil e do governo e passa a ter uma secretaria executiva dentro do Ministério do Meio Ambiente. Desde o início do trabalho da Comissão, do Grupo de Trabalho da transição de Comissão para Conselho, e do Conselho em si, a Articulação esteve envolvida, apesar da dificuldade das raizeiras em serem reconhecidas enquanto comunidade tradicional.

\section{Visões de futuro para a Articulação e para os povos tradicionais}

Diante das mudanças impostas governo atual, percebe-se uma intensa subtração dos direitos de todas as comunidades tradicionais, vide a retirada de recursos do governo para as reuniões do Conselho.

(...) pois a primeira coisa que o governo fez foi retirar os recursos para a gente não se reunir, porque a gente se organizava. (...) E aí, pra acabar com o Conselho Nacional de Povos e Comunidades Tradicionais foi fácil, porque ele depende muito do governo, a secretaria executiva tá lá dentro do Ministério

2 Ver Anexo 1.

DIGNIDADE RE-VISTA | ISSN2525-698X| 2018 | V. IV | N. 8 | Políticas Públicas e Direitos Humanos. 
ALVES, Carolina; REIMANN, Laura. As Políticas para os Povos Tradicionais à luz da experiência das Raizeiras do Cerrado - Articulação Pacari.

do Ambiente e dependia muito dos recursos do governo para se estar junto, pra se encontrar. (LAUREANO; DIAS, 2019)

Todavia, Articulação Pacari de Raizeiras do Cerrado, demonstra resistência ao desmantelo de suas políticas sociais, mantendo vivas as suas práticas. No intuito de proteger seus conhecimentos tradicionais, as raizeiras continuam a participar de eventos e reuniões locais, buscando manter a democracia e os espaços participativos das comunidades tradicionais. $^{3}$

Ademais, é importante ressaltar que o bioma do Cerrado, local onde vivem as raizeiras, encontra-se em estado de alerta devido ao desmatamento descontrolado - média anual de 1,5\%, o que representa 3 milhões de hectares ao ano (MACHADO, 2004) - que reduziu de forma gritante a área de vegetação nativa da região. O Cerrado, conhecido como savana brasileira, abriga um grande número de espécies endêmicas da fauna e flora, pois apresenta uma ampla heterogeneidade espacial, o que faz com que sua destruição tenha um impacto ainda maior, pois levaria a extinção de inúmeras espécies.

De acordo com a raizeira entrevistada Lourdes, o desmatamento da região tem sido sentido, pois a destruição da biodiversidade local dificulta a manutenção da aplicabilidade do conhecimento obtido pelas raizeiras, pois já não encontram mais as espécies que precisam no lugar onde elas costumavam existir.

Dessa forma, o aumento das pressões antrópicas tem levado um dos maiores hotspots de biodiversidade do planeta à sua destruição, o que promove um efeito cascata que afetará além da rotina das comunidades da Articulação Pacari, mas o meio ambiente como um todo. Portanto, planos de manejo e uma intensa restauração florestal são requeridos, para que haja a mínima recuperação da vegetação nativa deste bioma. Devido à escassez de dados científicos sobre a restauração do Cerrado, as normas que tratam do assunto ainda são pouco eficazes. Muito do que se vê no Manual para Recuperação da Vegetação do Cerrado (ICMBio, 2011) não tem sido instaurado. Ainda, com o esvaziamento de órgãos como o IBAMA, enfraquecese qualquer ação em prol da preservação do meio ambiente, deixando a população da região e as comunidades de fauna e flora - que dependem desse hábitat íntegro -, à mercê de uma politicagem baseada no antropocentrismo exacerbado de poucos.

Dados os interesses conflitantes dos Povos e Comunidades Tradicionais e dos setores da sociedade interessados na exploração da terra e de recursos naturais, nos quais os primeiros primam pela defesa do território e manutenção do seu modo de vida, enquanto os últimos visam

\footnotetext{
3 Ver Anexo 2.
} 
a exploração de recursos para o lucro, já mencionados anteriormente, garantir a manutenção de direitos adquiridos e tentar se garantir novos direitos se torna uma tarefa árdua. Não faltam tentativas de representantes de setores como a agricultura, mineração, e outros exploradores, de acabar com os direitos dos povos e comunidades. Em 2018, a Frente Parlamentar da Agricultura enviou uma carta ao Presidente Michel Temer pedindo a revogação do Decreto 6.040, sob os argumentos de que o conceito de povos e comunidades tradicionais é permissivo a afrontas à ordem e a segurança e viola a garantia constitucional de proteção à propriedade privada. Porém a carta não surtiu tanto efeito, dada a vigência da política até então. Como um de seus primeiros atos no governo, o atual presidente Jair Bolsonaro publicou uma Medida Provisória acabando com diversos espaços participativos, entre eles o Conselho Nacional de Desenvolvimento Sustentável dos Povos e Comunidades Tradicionais. E como esse é responsável pela implementação da Política, sua extinção pode abrir precedente para a revogação da Política, sob o argumento que a ausência do Conselho pode enfraquecê-la, torná-la ineficiente, uma vez que esse é responsável por avaliar a sua implementação.

\section{Conclusão}

O artigo teve como principal objetivo trazer ao público informações acerca da realidade política dos Povos e Comunidades Tradicionais do Brasil, à luz da Articulação Pacari. A dificuldade do acesso a informações a respeito da vigência do Conselho Nacional de Povos e Comunidades Tradicionais e suas pautas discutidas em reuniões e encontros - tendo em vista que a última ata da comissão publicada é de 2013 -, trouxe dúvidas a respeito de sua efetividade atual. A entrevista com as representantes da Articulação Pacari traz o ponto de vista da comunidade estudada nesse artigo em relação à atuação da Comissão e do Conselho e sobre os desafios da implementação do Decreto 6.040, que teria como principal objetivo proteger, reconhecer e fortalecer os direitos territoriais, sociais, ambientais, econômicos e culturais dos povos e comunidades tradicionais.

Os desafios em termos de políticas públicas para esses povos e comunidades é grande, uma vez que a Comissão Nacional de Desenvolvimento Sustentável de Povos e Comunidades Tradicionais (CNPCT) foi extinta pelo atual governo Bolsonaro com o Decreto Presidencial 9.759 e, com isso, talvez se tenha maior base de legitimidade para revogação da Política Nacional de Desenvolvimento Sustentável dos Povos e Comunidades Tradicionais (PNPCT). Isso denota mais um desmonte da legislação socioambiental, que já se encontra bastante 
ALVES, Carolina; REIMANN, Laura. As Políticas para os Povos Tradicionais à luz da experiência das Raizeiras do Cerrado - Articulação Pacari.

enfraquecida. Essas questões fragilizam a manutenção do tão rico conhecimento detido pelos povos e comunidades tradicionais, que se apresenta como uma alternativa para restauração do estado calamitoso encontrado em nossos remanescentes florestais.

Com isso, o usufruto dos espaços participativos da Articulação Pacari como grupo ativo no Conselho - e de outros grupos representantes das comunidades tradicionais - pode fazer frente ao governo brasileiro, trazendo a resistência e a força desses povos na luta por seus direitos e agregando conhecimento para sociedade brasileira como um todo. 


\section{Referências bibliográficas}

BANDEIRA, M. N; CAMPOS, F. I. Vista do Bioma Cerrado: relevância no cenário hídrico brasileiro. Disponível

em: <http://anais.unievangelica.edu.br/index.php/CIPEEX/article/view/3093/1215>. Acesso em: 17 out 2019.

BRASIL DE FATO. Bancada ruralista arma mais uma ofensiva contra povos tradicionais. Brasil de Fato, 2018. Disponível em:

https://www.brasildefato.com.br/2018/08/21/bancada-ruralista-arma-mais-uma-ofensivacontra-povos-tradicionais. Acesso em: 26 jun 2019.

BRASIL. Decreto $n^{o}$ 6.040, 2007. Disponível em: <http://www.planalto.gov.br/ccivil_03/_Ato2007-2010/2007/Decreto/D6040.htm> Acesso em: 28 jun 2019.

CUNHA, M. C. Relações e dissensões entre saberes tradicionais e saber científico. Revista USP, São Paulo, n.75, p.76-84, 2007. Disponível em: $<$ https://www.google.com/url? sa=t\&rct=j\&q=\&esrc=s\&source=web\&cd=1\&cad=rja\&uact=8 \&ved=2ahUKEwiX7ezI2qblAhUCVa0KHYBWBAcQFjAAegQIBBAC\&url=http\%3A\%2F $\%$ 2Fwww.revistas.usp.br\%2Frevusp\%2Farticle\%2Fdownload\%2F13623\%2F15441\%2F\&usg $=\mathrm{AOvVaw} 22 \mathrm{~F} 3 \mathrm{xwdFn} 70 \mathrm{q} 7 \mathrm{uVO}$ SSc2ss $>$. Acesso em: 18 out 2019.

DIEGUES, C. A.; ARRUDA, S. V. R.; SILVA, V. C. F.; FIGOLS F. A.; ANDRADE, D. Os Saberes Tradicionais e a Biodiversidade no Brasil. Nupaub - USP, Probio - MMA, CNPq, 2000.

ELISABETSKY, E.; SOUZA, G. C. Etnofarmacologia como ferramenta na busca de substâncias ativas. In: SIMÕES, C. M. O.; Schenkel, E.P.; Gosmann, G.; Mello, J.C.P.; Mentz, L.A. \& Petrovick, P.R. (Orgs.) Farmacognosia: da planta ao medicamento. 5.ed. Florianópolis: UFSC, 2004.

LAUREANO, Lourdes; DIAS, Jaqueline. Entrevista concedida a Carolina Alves e Laura Reimann. Rio de Janeiro, 31 mai 2019. [A entrevista encontra-se transcrita no Anexo 1 deste artigo]

Entrevista concedida a Laura Reimann. Rio de Janeiro, 15 jun 2019. [A entrevista encontra-se transcrita no Anexo 2 deste artigo]

MACHADO, R. B. et al. Estimativas de perda da área do Cerrado brasileiro. Relatório técnico não publicado, 2004. Conservação Internacional, Brasília.

MINISTÉRIO DA SAÚDE. Programa Nacional de Plantas Medicinais e Fitoterápicos. Ministério da Saúde, 2009. Disponível em: <http://bvsms.saude.gov.br/bvs/publicacoes/programa_nacional_plantas_medicinais_fitoterap icos.pdf>. Acesso em: 14 junho 2019. 
Comitê Nacional de Plantas Medicinais e Fitoterápicos. Disponível em: $<\mathrm{http}: / /$ www.saude.gov.br/acoes-e-programas/programa-nacional-de-plantas-medicinais-efitoterapicos-ppnpmf/politica-e-programa-nacional-de-plantas-medicinais-efitoterapicos/comite-nacional-de-plantas-medicinais-e-fitoterapicos>. Acesso em: 14 junho 2019.

ICMBIO. Manual Para Recuperação Da Vegetação De Cerrado. 2011. Disponível em: $<$ http://www.icmbio.gov.br/educacaoambiental/images/stories/biblioteca/permacultura/Manua 1_recuperacao_cerrado.pdf> Acesso em: 26 junho 2019.

PACARI. Farmacopéia Popular do Cerrado. Articulação Pacari. Disponível em: <http://www.pacari.org.br/farmacopeia-popular-do-cerrado/>. Acesso em: 14 jun 2019.

- Nossa História. Articulação Pacari. Disponível em: <http://www.pacari.org.br/articulacao-pacari/historia/>. Acesso em: 14 junho 2019.

Políticas Públicas. Articulação Pacari. Disponível em: <http://www.pacari.org.br/articulacao-pacari/politicas-publicas/>. Acesso em: 18 out 2019.

PRANCE, G.T. Ethnobotany today and in the future. In: SHULTES, R. E.; REIS, S. Von (Eds.). Ethnobotany: evolution of a discipline. New York: Chapman \& Hall, 1995. p.60-7. 


\begin{abstract}
Anexo 1 - Transcrição áudio de entrevista com Lourdes Laureano e Jaqueline Dias
Carolina Alves: Nós pesquisamos e achamos muito poucos dado sobre a Política [Política Nacional de Desenvolvimento Sustentável dos Povos e Comunidades Tradicionais], e tudo muito confuso a não tão atualizado. Como você enxerga o trabalho da política? Como foi o processo de participação da Articulação na formação da Política?
\end{abstract}

Lourdes Laureano: A primeira iniciativa de organizar foi lá em Goiás, em Luziânia, em um encontro que reuniu as principais lideranças de povos e comunidades tradicionais, que viviam e se sentiam até então invisibilizados pelas políticas públicas e pela sociedade em geral, sobre onde elas vivem, o que fazem, quais as dificuldades e demandas. Então a partir daí formou-se uma Comissão, deu-se [a ela] esse nome Comissão Nacional dos Povos e Comunidades Tradicionais, que tinha como tarefa avançar para um Conselho, no futuro, e formular as diretrizes, as bases, de uma Política Nacional para o Desenvolvimento dos Povos e Comunidades Tradicionais. Então, como a Comissão ficou desde 2005 até 2016, no apagar das luzes do golpe, no último dia da Dilma Roussef como presidente que ela assinou [o decreto] dando assento ao Conselho. Teve-se então uma transição de Comissão para Conselho, que tem uma grande importância, já que o último tem um corpo de participação da sociedade civil e do governo, tem uma secretaria executiva dentro do Ministério do Meio Ambiente, então era importante que se institucionalizasse como Conselho. Dentro do Conselho, que tinha 28 segmentos (quilombolas, povos indígenas, ribeirinhos, geraizeiros), a gente teve uma dificuldade de colocar no Conselho o segmento das raizeiras como um segmento de comunidades tradicionais, mas por fim conseguimos. Porém foi muita luta, um processo imenso de transição da Comissão para Conselho, onde perdemos muito tempo, com a criação de um GT, que atuamos muito fortemente, para fazer o estatuto e todas as normas. Mas teve muito pouca efetividade, não é à toa que tem muito pouco dado.

Carolina: Isso que eu ia perguntar [sobre a efetividade], porque a gente achou poucos dados. Lourdes: Praticamente, não avançou, demorou tanto a se constituir que agora neste governo, nesse desmonte, a primeira coisa que ele fez foi atacar, destituir todos os espaços participativos, um foco central na destituição e eliminação desses espaços. Todavia, está tendo muita resistência. O Conselho na verdade serviu pra gente se conhecer, a gente tinha muita ciência da importância dos nossos modos de vida, dos nossos valores, do nosso papel de usar e proteger a biodiversidade, da importância de sermos diversos, da responsabilidade no uso da biodiversidade. Então, nós nos conhecemos, e num Brasil tão grande. Nós não tínhamos muita noção, pra quem vive no sertão do cerrado onde falta água, lá no Jequitinhonha, nós fomos conhecer os ribeirinhos lá da Amazônia, que remam nos igarapés, ou o pescador da costa da Bahia, as marisqueiras no Pará, os quilombolas e toda sua questão fundiária, a luta pelo reconhecimento dos seus territórios, os povos indígenas. Isso foi enriquecedor, a gente se conheceu, e vimos que somos fortes porque somos diversos. E essa diferença de onde a gente atua, onde a gente vive, foi muito importante, até para fortalecer a nossa própria identidade, saber que lá no Pará tem muita raizeira, lá no Rio Grande do Sul tem muita raizeira, em toda costa, os pantaneiros, isso foi o que ficou de forte. Hoje, o governo tentou reduzir a Comissão a 12 segmentos, depois recuou e ficou em 22, e hoje estamos tentando sobreviver, não aceitar esse desmonte. Nós próprios consideramos que existimos em 22 e muito mais, pois 22 são os que estão reconhecidos no Conselho, mas tem muito mais do que isso, o Brasil é muito rico. Imagina um Brasil desse tamanho, quantas formas de vida diferentes que tem de existência em seus territórios, as variadas lutas. Então, hoje o Conselho está parado, foi extinto, mas está retomando, parece que eles voltaram e estão saindo informes na mídia, do conselho. Estamos tentando uma Frente Parlamentar dos Povos e Comunidades Tradicionais, com o apoio do PSOL nas reuniões, pois a primeira coisa que o governo fez foi retirar os recursos para a gente 
não se reunir, porque a gente se organizava.

Carolina: Claro, pois se vocês não se reúnem não fazem frente a eles.

Lourdes: A gente se reunia sistematicamente em Brasília, tinha quatro ou cinco reuniões por ano, fora a busca de recursos para reuniões locais. E agora parece que o PSOL entrou com o apoio, e estão tentando buscar uma Frente Parlamentar para poder fazer frente ao governo. Por que essa história de reduzir o conselho? Acabaram com o Consea, que é da alimentação, um conselho muito forte e muito importante. E aí, para acabar com o Conselho Nacional de Povos e Comunidades Tradicionais foi fácil, porque ele depende muito do governo, a secretaria executiva está lá dentro do Ministério do Ambiente e dependia muito dos recursos do governo para se estar junto, pra se encontrar. Então é isso, não é à toa que tem poucos informes. Mas a gente atuou muito forte lá, tem uma diretriz lá na Política que fala do direito dos povos e comunidades tradicionais praticarem a medicina tradicional, a gente atuou para incluir esse item.

Jaqueline Dias: Eu lembro que quando foi feito esse texto da política teve uma disputa muito grande, a gente tinha uma proximidade com a secretaria executiva, então a gente tentava colocar várias questões, mas tinha muita negociação. Por exemplo, foi só essa "frasezinha", porque o Ministério da Saúde não deixava passar mais além disso, então foi uma política muito negociada. Uma questão interessante do Conselho para vocês pensarem é o quanto essa Comissão, a vida dessa Comissão, pautou as pautas realmente dos povos e comunidades tradicionais e o quanto essa Comissão, esse Conselho, ficou atrás das pautas do governo? Que é o que a gente mais viu. Porque tinha uma pauta da questão territorial muito forte no início, e nós como medicina tradicional nem fomos mencionados. Então, a própria demanda dos povos e comunidades tradicionais é enorme, se você pega os 28 segmentos que estavam representados lá dentro pensa o tanto de demanda completamente diferente umas das outras né?! E isso gerou um conflito interno também, porque não é lindo - todo mundo amigo -, é uma disputa medonha sobre as pautas, disputa de poder lá dentro, disputa de representatividade lá dentro. É uma arena política como qualquer outra. E nisso, só um adendo, essa Lei 13.123 sobre o acesso à repartição de benefícios, acesso ao patrimônio genético, eu acho que ela roubou um pouco a pauta da Comissão, porque como foi uma coisa que tem muito a ver com povos e comunidades tradicionais, quer dizer eu vou pegar o seu conhecimento tradicional e vou transformar em um produto, em um cosmético, você imagina. O governo colocou essa lei sem discussão nenhuma com as comunidades.

Carolina: Sendo que tinha que ter tido uma discussão, até mesmo devido à garantia de consulta da Convenção 169.

Jaqueline: Mas sabe quando que foi passada [a lei]? O executivo mandou pro Congresso na Copa do Mundo de 2014. E aí quando viu já tinha passado, então eles se sentiram na obrigação de participar do processo de regulamentação desta lei. Que foi quando a lei foi ter a sua regulamentação.

Lourdes: Sim, é verdade, o governo usou essa base imensa, que ele pouco contribuiu para formar, para legitimar, pra ir atrás dessa regulamentação. Tinha uma base, uma organização, pagava a passagem para a gente ir para os encontros no Brasil todo, para regulamentar a lei. Eu acho que vocês deveriam buscar os segmentos, sabe? Ver os principais segmentos, e em que momento cada segmento pode ver a sua demanda contemplada lá dentro do Conselho.

Jaqueline: Ou seja, nenhuma!

Lourdes: Nós tivemos muita dificuldade, porque nossos inimigos são fortes né?! Nossos opositores, por assim dizer.

Carolina: Até porque vocês estão lutando contra medicina, farmácia, contra um lobby industrial imenso.

Lourdes: Contra a indústria farmacêutica!?! Então a gente teve muita dificuldade, até entre nós, de ser reconhecido como um segmento de comunidade tradicional, que traz conhecimento 
tradicional.

Carolina: E esse reconhecimento de vocês enquanto comunidade tradicional sempre existiu ou foi algo mais recente?

Lourdes: Olha, sempre existiu a consciência de que esse conhecimento era tradicional, é tradicional, sempre tivemos essa coisa da identidade da raizeira fortemente atuando no meio. Só não tinha um espaço de participação. Não falava que tinha um assento em um Conselho de Povos e Comunidades Tradicionais. Mas sempre nós reconhecemos como detentoras de conhecimento tradicional, porque é o que nos identifica mais fortemente como raizeira é determos conhecimentos que a sociedade não tem.

Laura Reimann: Como vocês passam isso agora adiante? É uma coisa passada de geração a geração? Isso tem registros? Vocês escrevem sobre?

Lourdes: Sim, nós temos uma publicação que chama Farmacopeia Popular do Cerrado. Nós demos o nome de farmacopeia porque é um nome político, o Brasil tem uma farmacopeia oficial, e nós fizemos a farmacopeia popular, porque na farmacopeia brasileira pouco tem do uso de plantas, do uso da biodiversidade, que é o que a gente mais usa lá na ponta, dentro da comunidade. O pessoal da Anvisa ficou muito puto, queriam que a gente tirasse esse nome, que esse nome era uma afronta à Anvisa, a agência que regula isso, deveria ser um Guia de Plantas Medicinais, queriam destituir o conteúdo político do nosso trabalho. Então a gente registrou, 262 raizeiras e raizeiros fizeram o registro do seu conhecimento, como uma forma de proteger, um sistema sui generis de proteção do conhecimento. E publicamos o Protocolo Comunitário, não sei se vocês conhecem? Nele a gente expõe a nossa demanda por assegurar o direito de praticar, o direito consuetudinário, que vem do costume, de praticar.

Jaqueline: Eu queria responder um pouquinho essa coisa da transmissão, porque é uma coisa que a gente conversa muito. Porque antigamente era muito assim, era só a transmissão da avó que passava pra netinha, que ficava andando ali. Só que a sociedade também começa a ter outras formas, uma coisa que a gente vê hoje é que não tem muito mais esse repasse porque o jovem não fica mais na comunidade, mas por outro lado a gente fala que a organização social, a formação de grupos de mulheres, que não existiam antigamente, em farmacinhas comunitárias, é uma forma de transmissão de conhecimento. Então a forma da transmissão de conhecimento ela também muda, não é da mesma forma, e a organização social, hoje, é um instrumento da transmissão de conhecimento.

Lourdes: E, também, assim, o conhecimento tá muito ligado à biodiversidade. E o que a gente vê, esse desmatamento, essa destruição da biodiversidade local, onde essas detentoras de conhecimento vivem, não acaba com a transmissão, mas fragiliza. Porque imagina você, uma raizeira que quer mostrar um pé de angico para um jovem, pra saber como tirar a casca, de repente não tem mais o pé de angico que ela tem costume de usar.

Jaqueline: Uma coisa que eu estava lembrando, sabe uma coisa que é da transmissão hoje? As redes sociais. Toda raizeira tem um zap zap. E isso atrai muito os jovens. Tem grupo que vende os remédios, elas anotam os pedidos, quais os produtos vendidos.

Carolina: $\mathrm{O}$ apoio de vocês vem de onde?

Lourdes: Vem de projeto, editais, entidades de apoio.

Jaqueline: Sabe, chega uma época também que é assim: você vive pra fazer projeto e gestar projeto ou você realmente vai viver lá o campo. A farmacopeia a gente ficou dois anos escrevendo. Tem hora também que a gente tem que optar assim, deixar fluir mais. 


\section{Anexo 2 - Questionário adicional a Lourdes Laureano feito por e-mail}

\section{As raizeiras têm algum apoio institucional ou político?}

R: As raizeiras recebem apoio financeiro de organizações como o Instituto Sociedade Populações e Natureza (ISPN), através do Programa de Pequenos Projetos Ecossociais PPPECOS, do PNUD; da Fundação H. Boll, da Fundação Luterana de Diaconia (FLD). Como parceiras de projetos, desenvolvemos atividades com a Rede de Intercâmbio de Tecnologias Alternativas (REDE). Participamos de espaços coletivos como no GT-Biodiversidade da Articulação Nacional de Agroecologia (GT-Bio/ANA), e da Rede Cerrado.

\section{Como foi financiada a farmacopeia? Contaram com recursos públicos, passou pela} Comissão/Conselho, chegaram a acessar outras políticas foi algum edital público...?

R: A Farmacopeia Popular do Cerrado recebeu apoio do governo para a sua publicação (MMA). Para o trabalho de pesquisa em campo, sistematização coletiva, realização de encontros locais, regionais e nacionais tivemos o financiamento de várias entidades de apoio como a CESE, PPP-ECOS, MISEREOR, através de projetos enviados diretamente às entidades. Não participamos de edital público.

\section{Como têm sido as ações das raizeiras com ou apesar do poder público?}

R: A Articulação Pacari, como representante do bioma Cerrado, teve assento no Comitê Nacional de Plantas Medicinais e Fitoterápicos, desde a criação desse Comitê, e conseguiu inserir a diretriz 10 que se refere aos remédios caseiros.

Participou da Comissão Nacional de Povos e Comunidades Tradicionais (CNPCT) desde a sua criação, passando pelo GT transição de Comissão para Conselho Nacional para o Desenvolvimento de Povos e Comunidades Tradicionais (CNPCT) fazendo parte dos 28 segmentos participantes do CNPCT. Como integrante do CNPCT, atuou ativamente na regulamentação da Lei 13.123/2015, Lei de Acesso ao Patrimônio Genético e aos Conhecimentos Tradicionais Associados e Repartição de Benefícios, principalmente lutando pelo direito de consulta livre, prévia e informada aos povos e comunidades tradicionais e pelo livre acesso à biodiversidade local.

\section{Para vocês, o Conselho atendeu as pautas dos povos e comunidades tradicionais ou atendeu as pautas baseadas nos interesses do governo?}

R: Apesar de o Decreto 6040 ter sido uma grande conquista da organização dos povos e comunidades tradicionais e de ter uma representação legítima, atuante e consciente de seus direitos, desde a criação da Comissão, o Conselho não conseguiu muita efetividade em suas ações propostas em suas diretrizes, por falta de apoio financeiro e autonomia, e por manter-se atrelado ao poder público, não conseguindo efetivar suas pautas. Infelizmente, tivemos dificuldades para instituir o Conselho e implementar a Política nacional de povos e comunidades tradicionais. O próprio CNPCT foi assinado somente em 2016, e não teve tempo de pautar suas demandas, ficando até então cumprindo uma pauta do governo, através de sua secretaria executiva que tinha assento no MMA. Exemplo disso foram as oficinas realizadas pelo MMA, para a regulamentação da Lei 13.123/2016, que foram consideradas pelo governo como uma consulta aos PCT's, mas que, na verdade, foram oficinas de capacitação para que os PCT's pudessem tomar conhecimento de uma Lei que foi elaborada sem a participação dos povos e comunidades tradicionais, apesar de ser uma lei que está diretamente relacionada aos conhecimentos tradicionais e aos modos de vida dos PCT's. Após o golpe que destituiu o governo da presidenta Dilma, os espaços de participação foram sendo estrangulados até o total 
colapso que acontece no atual governo do Bolsonaro. Perdemos então ainda mais o controle social e os espaços duramente conquistados, sem termos tempo de atuar e desenvolver as nossas pautas.

\section{Como a Articulação Pacari tem lidado com o governo Bolsonaro e os ataques a} sociedade civil e aos povos e comunidades tradicionais?

R: No atual governo, que tanto ameaça a democracia e os espaços participativos, com o desmantelo das principais políticas sociais, das políticas públicas no campo da educação, saúde, meio ambiente, e dos direitos da mulher, e avança com uma ofensiva intolerável, subtraindo os direitos dos povos indígenas, quilombolas e de todas as demais comunidades tradicionais, a Articulação Pacari de Raizeiras do Cerrado, encontra-se na resistência, mantendo vivas as suas práticas, participando de eventos e reuniões junto à parceiras de nosso trabalho. Focamos mais em ações locais, buscando articular em redes locais, para fortalecer e proteger os seus conhecimentos tradicionais e os seus modos de vida. Existir passou a ser um ato de grande resistência.

6. Vocês participaram da inclusão do Art. 30-inciso VII - "garantir aos povos e comunidades tradicionais o acesso aos serviços de saúde de qualidade e adequados às suas características socioculturais, suas necessidades e demandas, com ênfase nas concepções e práticas da medicina tradicional"?

R: Sim, participamos ativamente da construção das diretrizes do Decreto 6040, e, principalmente deste inciso, relativo à garantia das práticas tradicionais de saúde. A Pacari tinha uma representação, na construção das diretrizes no eixo saúde, e enviamos essa proposta que foi incorporada neste artigo. 